\title{
Conceptual Principles of Education for Sustainable Development
}

\author{
Iryna Karpan ${ }^{1}$, Nataliia Chernikova ${ }^{2}$, Tetiana Motuz ${ }^{3}$, Boris Bratanich ${ }^{4}$, \\ Tetiana Lysokolenko
}

\begin{abstract}
Education has an important place in transitional strategy of society to sustainable development that is proved by many international acts. In the outlines of modern approaches, education for sustainable development is characterized as innovative concept of changes to educational activity, as mechanism of realization of strategy of sustainable development, as instrument of modernization of educational practice, as one of the basis of modern educational quality and continuity standards. National system of global aims for consolidation of society of sustainable development with an accent on the significance of educational matter was created in Ukraine. Education for sustainable development is characterized by being part to structure creating social institutes of modern society, transversality, subjective direction, integrativity, forward-looking character. This vector of education research is same with global man's intentions of civilization development - increase in human's value in all spheres of life, developing of democratic management, constructive cooperation and communication, etc. Among multidimensional potential of researched phenomenon the most practical value has environmental education. As for today, environmental education is a practical mechanism of transformation of educational system on the principles of sustainable development. Environmental education is seen as an instrument for systematic formation of man's basic attributes for being part of education for sustainable development field - critical thinking, environmental worldview, subjective-value approach to environment, eco-cultural values. Cumulative result of environmental education is formation of environmental culture.
\end{abstract}

Key words: education, sustainable development, environment, ecology, synergetic, culture, bumanism.

\section{Introduction}

Formation of society based on postindustrial principles for sustainable development changes status and functions of educational activity, which found its reflection in the content of "educational society". One of the aspects of transformation of the educational system into an integrative subsystem of postindustrial society is an essential growth of its projecting-modeling functions towards social development. In the context of increasing of global problems and conflict-generating threats on personal level the task of preventing all specters of dangers with the means of educational resources

${ }^{1} \mathrm{PhD}$, Prof. Asoc., Department of Social and Humanitarian education in Dnipro Academy of Continuing Education. Ukraine

${ }^{2} \mathrm{PhD}$ in History, Doctoral Student, Oles Honchar Dnipro National University, Ukraine

${ }^{3} \mathrm{PhD}$, Prof. Asoc., Department of General, Special Pedagogy, Rehabilitation and Inclusive Education in Dnipro Academy of Continuing Education. Ukraine

${ }^{4}$ Doctor of Philosophy, Professor, Department of Psychology in Dnipro Academy of Continuing Education. Ukraine

${ }^{5} \mathrm{PhD}$, Prof. Asoc., Department of Philosophy in Dnipro Academy of Continuing Education. Ukraine (Corresponding author). 
becomes one of top-priority. Functions of threats prevention mechanism and transition to new quality of social development are conducted by education, which must transform into new quality - education for sustainable development.

\section{Literature Review}

A great amount of works of the problematic of education for sustainable development can be observed. Scientific discourse about education for sustainable development has more than 30 years of history and has started at the end of $20^{\text {th }}$ century in works of such foreign scholars as D. Vortman, R. Makkeun, T. Simkin, D. Tilbery, C. Hopckins, M. Fernari, K. Shepard, K. Sherren and others. In practical-educational field scientific intelligence concentrate around 3 main vectors of researches: general guidelines about tasks and role of such education (J. Nikel, M.Mellmann, J. Rockstrom, J. Hart), particularities of educational models (L. Balog, V. Bruner, M. Busli, J. Farli, P. Harland), clarifying of an integrative approach in education for sustainable development (K. Genderson, D. Tilburi).

In the modern scientific space, the problem of education for sustainable development is cross-curricular and sufficiently developed, and it is given attention by scientists from different scientific fields. In a survey called "Education for Sustainable Development: Evolution and Perspectives: A Bibliometric Review of Research, 1992-2018", the authors point to the vast number of works on education for sustainable development that have been written by scholars in various fields of science. The analysis allowed the authors to argue that the focus of research attention in general is made on the integration of education in sustainable development or sustainable development in education itself (Grosseck, Tî̀ru \& Bran, 2019). J. O'Flaherty \& M. Liddy (O'Flaherty \& Liddy, 2018) consider the relationship between education and development of education for sustainable development itself. The authors of the paper "Academics in the Field of Education for Sustainable Development: Their Conceptions of Sustainable Development" note that researchers in the field of education for sustainable development are not inclined to approach the phenomenon of sustainable development conceptually, but only focusing on its individual areas (Sinakoua et al., 2018). Researchers Dlouháa, J, Pospíśilováb, M. focused on examining the competencies that are required in the modern world to develop education for sustainable development (Dlouháa \& Pospíśilováb, 2018). Accordingly, we can assume that, despite the presence of a huge body of diverse research material, the problem of conceptualizing education for sustainable development at the methodological level remains not sufficiently researched.

Analysis of conceptual principles of education for sustainable development in methodological plan is defined by the task of coordination of efforts of society about formation of valuable principles of activity of each person according to social needs and global tendencies of society's development in the vector of creating of noospheric civilization. Guidelines about personal area of educational activity, life and development as a sphere of self-actualization of a personality, existential nature of problems of interaction between personality, society and nature have the biggest methodological value for analysis of education for sustainable development. Methodological guidelines about 
interconnection between the content of education for sustainable development and society are used for analysis of sociocultural dependence of establishment of its theory and practice.

\section{Development}

Imperative of humanity's survival in $21^{\text {st }}$ century must mean the imperative of transitioning into new consistency of socio-natural evolution, which mechanisms have a dominance inside processes of harmonization been transferred to social intelligence. Society's management of future is conducted exactly by the means of social intelligence as a new socio-scientific and philosophical category in function-evolutional sphere. Mechanism of replication of social intelligence, which substance is knowledge, is education as social and civic institution, connected to the imperative of global-civic mentoring of a person. This imperative is connected with moral-noospheric imperative, which outlines the necessity of formation of the first steps of socialization of new neoclassical morality from person's early childhood. In this imperative's system of values and priorities the in-depth synthesis of morality, spirituality and intelligence is conducted. The transition to noosphere needs a formation of new mindset, which is connected to the necessity of making noospheric-ecological imperative that must become the basic requirement of human and nature coevolution, law of supporting person's social-natural entirety. The need of obtaining of positive results lies in accepting of this imperative by the whole world society.

On the modern stage of humans' development there is a great need in learning of humanitarian potential of national and world cultures, accepting and using new scientific, educational and cultural paradigms on practice, that are oriented on establishing of universal erudition the will let people take the responsibility for socio-natural harmony. So, the strategy of sustainable development has the transition from material civilization that fosters and cultivates system of materialistic, consumptive values to spiritual civilization that needs the inheritance of imperatives mentioned above as its aim. This changes the character of educational process at its core, and the education for sustainable development is the mechanism for these changes, adapting of educational system to the needs of "knowledge society".

Education takes an important place in society's transition strategy to sustainable development. In 2015 UN Summit has defined 17 aim of sustainable development for 2015-2030. Education came out not only as a separate aim, but also as an element in all others. In order to realize educational functions as an instrument for establishing of society of sustainable development UNESCO established goals of education for sustainable development in outlines of each aim in 2017 (Education for Sustainable Development Goals, 2017). Their analysis shows that this process essentially expands functions and value of education as a social institute in general. This can be especially watched in outlines of implemented Global Action Programme on Education for Sustainable development by UNESCO (Global Action Programme (GAP) on Education for Sustainable Development (ESD), 2014). This program is oriented for radical increase of attention at the usage of education as a mechanism of implementing of sustainable development by the means of interpenetrating of general educational and social 
innovations. In the outlines of modern approaches education for sustainable development is characterized also as an innovative concept for changes in educational process, an instrument of systematic modernization of educational practice, and one of the basics of modern educational quality and continuousness' standards. Accenting on the attribution of forward-looking character of education for sustainable development, researches are emphasizing its next conceptual structures: conceptual approach, future orientation interdisciplinary, forward-looking education, pragmatic approach, subjective activity, responsibility formation orientation, usage of projective technologies (Nikolaev, 2015:119-120).

This problem is actual for our country too. By signing UNCED documentation Ukraine has undertook serious obligations according realization of program of global cooperation that was adopted by consensus. Ukraine faces unprecedented task - to realize sustainable development model which was adopted by the entire world after UNCED, because the sustainable development term includes all-side balanced harmonious development. It is worth mentioning that in 2016 national system of global goals of establishing the society of sustainable development was adopter in Ukraine and consists from 87 goals and 172 exponents, that also includes educational component that consists from 7 goals and 11 exponents (Education for Sustainable Development Goals 2017).

As mentioned by national researcher I. Korneva, "education for sustainable development in terms of country's realities must function as a direct generator of new socioeconomical genesis and product social, ecological and economic changes in direction of sustainable development" (Korneva, 2018:113).

There are a lot of approaches to understanding sustainable development, but today most of the scholars appealed to the attributive definition by the aims of society's transition to sustainable development. Thus it is seen as a separate type of educational activity and does not come to knowledge about sustainable development. It is more of an instrument for education to use in order to obtain sustain in different spheres (McKeown, 2006).

Scholars define particularities of this type of education according to tasks of creating new system of values, social relationships and people's mentality. It must be based on integration of economical, natural and social development, constituted variety; responsibility, subjective activity; combination of local and global cultural values; integration of educational process (Andersone, 2015). Thus it can be stated the belonging of characteristics of the so-called postnonclassical education to the education for sustainable development - future orientation, interactivity, subject-subject relations, practical orientation, interdisciplinarity and so on.

Modern understanding of education for sustainable development was formed as a result of practical actions aimed for its adoption. In the first period of establishments of values for society of sustainable development education for sustainable development was seen as a form of organization of educational process (Agenda for the 21st Century, 1992). Later it was interpreted as a new direction of "education for everyone" (Bonn Declaration, 2009). Today the thought that it shows new socially determined ability and quality of educational process is been introduced more and more.

Education for sustainable development is a form of educational activity in modern circumstances. Its aim is preparation of society and person to supporting society's stability, realization of strategy of human and nature's coevolutional development. 
National researcher K. Nikolaev states, that "education for sustainable development is based on understanding of sustainable development as one that fulfills needs of these days and does not threatens the ability of future generations to fulfill their own needs" (Nikolaev, 2015:117-118). It is better to consider as special type of education with its own specific quality, values, instruments, which realize substantial integration of ecological, social and economic vectors. This type of education is characterized by belonging to social institutes, which are creating structures of modern society. It is also characterized by transversality, subjective orientation, integrativity, forward-looking character. It can be defined as a postnonclassical education of transversality type that has subjunctive-personalistic orientation realized through prism of values of sustainable development. Constitution of sustainable development on attributive basis as a quality of society's education must be considered as a main tendency of its development. Thus global trend of its development is its transformation from element (or form) of modern education into its general representation through new values, new sense and new content of educational activity.

Education for sustainable development can be considered as a representation of modern humanism because it's directed for effective combination of different interests from the perspective of human's genuine interests under globalization conditions. With the help of values of sustainable development it is only possible to create society that bears humanitarian character. In this sense education for sustainable development is like a map of formation of future humanity based on humanitarian principles. From the other side, this vector of education's development clearly synchronizes with global human-measured intentions of civilization's development - growth of human's significance in all spheres of life, development of democratic management, constructive cooperation and communication etc.

Famous Ukrainian researcher O. Pometun states, that today education for sustainable development shows up not by its own content, but by its focus and commitment in general global processes, and thus "main task of teachers during education for sustainable development is to educate in action and for action. It means giving pupils all the necessary skills for acting in sustainable development. First of all it is formation of harmonic connection between themselves and other people, world in general, to think and imagine in original, creative way" (Pometun, 2015:175). According to it realization it is not a task of implementation special disciplines, but constituting on new general approach to educational activity based on interdisciplinary principles. By the way, in most of European countries (Poland, Finland, Norway) this approach has already been used as a basis of formation of school curriculum and national educational standards.

Ukrainian scholar I. Sichko also stated, that "education for sustainable development is a modern approach to organize the educational process, that includes informing members of society about main problems of sustainable development; mindset formation, that is based on principles of constancy; reorientation of education from transferring of knowledge to dialogue establishing; orientation at stressing and practical solving of local problems of modern society" (Sichko, 2016: 173). Herewith, one of the dominating aspects is one connected with security and coping with threats and risks of developing of modern society. Education for sustainable development does its security function not by 
using others organizational activities, but by forming correct system of values and mindset on each exact person's level, and therefore on the society's level.

Resulting from such great varieties of content and functions scholars essentially expand specter and direction of changes in educational field for sustainable development. Researcher O. Khmelevskaya proposes "to concentrate on development of such institutions in educational sphere: refocusing of functional and subjective field of education; competence design; implementation of transformational pedagogy; supporting of educational agents; creating of sustainable educational environments; coordination and integration improvement; renewing of educational reform's content" (Khmelevskaya, 2018: 35)

As for global projects realization on national level, concrete innovational projects based on principles of sustainable development are of great importance in kingdom of changeable educational standards, monitoring and evaluation of realization of innovative educational programs on different levels (educational environment, educational resources, educational practice, educational activity's results, etc).

UN Commission on Environment and Development put forth 27 principles, defining rights and duties of countries in question of assuring of sustainable development. In order to judge the direction of country's development UN Commission has exploited evaluation criteria, in particular "humanitarian development index" that includes next figures:

\begin{tabular}{ll} 
- & life expectancy at birth; \\
- & GDP per caput; \\
- & percent of the adult population; \\
- & number of compulsory years at school; \\
\hline & number of people with higher education per 1000 people.
\end{tabular}

3 out of 5 figures are coherent with population's educational level. Attempts to understand modern complex, open, disruptive and variable world have come to need of new mindset conceptions that could become philosophical foundation for educational system. Several academic communities state that main role among such conceptions belongs to theory of universal evolutional patterns and self-organization of complex systems both natural and social and especially educational systems of synergetics.

It needs to be mentioned, that there are many scientific researchers about synergetics and its supplements. But methodological and practical fields of synergetics are still beyond field of research, which is raising valid questions about role of synergetics in becoming of new educational model. Synergetic reflexing of educational system is quite important, because education is in bifurcation zone, testing simultaneously next multidirectional influences as: labour market demands that lead to commercializing of education and diversification of educational structures; administrative-political demands of transitioning to Bolognese agreements; the need in transition to cyber virtual forms of education that correspond to modern educational society's demands; tendency to preservation of already formed educational traditions.

Coming to studying and researching synergetics paradigm, educational philosophy outlines problematic field at the crossing of several methodological approaches:

1. Social - problem of education and society interaction;

2. Cultural - education and cultural values; 
3. Anthropological - person's establishment in education;

4. Ontological - education as the global process.

Every approach has the definition of a concrete education's target as its aim that, therefore, must be expressed through set of tasks and pedagogical methods. Coherent picture of educational values and aims can be obtained through their conjunction. This will help to find gaps in order to sustain society's sustainable development.

In general, synergetical approach of researching modern educational problems can help to see vast conceptual and problematic field of educational process in its all four spheres simultaneously.

Formation of open educational system has the largest value for establishing of modern education for sustainable development in the context of synergetical methodology. As it was mentioned before, vision of a pupil as a strictly regulated and easily manipulated object is the weakness of modern technocratic educational system. Truly speaking, way of real education lies in opening pupil's personality to different spaces of senses and living aims, where personality creates and achieves them by itself. Education's quality in open educational system depends mostly from teacher's professional quality. New educational environment, new organizational structures in education, new educational technologies - all of these demands changes to teacher's professional requirements in open educational system.

The distinguishing characteristic of modern days is process of educational systems' systematical properties changes, increasing of its susceptibility to innovations in science and technology field connected with informatization of global community. In the middle of the second half of last century new conceptions of nonlinearity and chaos that satisfy to the idea of unrest have appeared. If modern scientific narrative is based on the open world theory, it will be quite appropriate to speak about openness of educational system. Human's openness comes from world's openness and appears by itself as an open, complex, self-organizing system and acts as a worldview.

Essential fault of traditional educational system lies in getting away from realization of human's cognitive purpose because of skewed nature of thinking strategy development and basing on hard differential way of knowing the world. Thus, according to modernity's requirements, education's task is to overcome individual and social consciousness stereotypes and change value-motivational paradigm in existing conditions that should become basement for new educational concept for creating mankind's survival conditions.

Giving educational system qualities of an open system has led to cardinal changes of its properties to the greater freedom while planning of studying, choosing place, time and tempo, in moving from "education for life" to "education through life" principle, in moving from pupil-to-knowledge to knowledge-to-pupil movement. "Education openness, - by Klepko S.F. definition, - is its ability to provide open space for personality development, for its coping with open world, free from ideological dogmas and banknotes, from euphemisms and understatements" (Klepko, 1998: 17).

Open education is understood as a system, where educational process is realized and achieving and confirmation of educational cense is done. Basement of educational process is formed by purposeful, controllable, and intensive self-guided student's work, who is able to study in convenient place for itself, by individual schedule, having a kit of 
special educational means and coordinated ability to contact with teacher using modern means of communication and technology. Traditional forms of education: on-site, offsite, externship - are integrating into a common educational space in open education system. Correctly used options of open education system can create a stable foundation for unstoppable studying through whole life. It can become an important step in creating of educational culture of $21^{\text {st }}$ century. Usage of synergetical approach lets to expand educational outlines, filling them up with moral context; education is an endless process of human's comprehension of itself and its environment.

One of the aspects of philosophical-educational analysis of education for sustainable development is research of mechanisms of its influence on postnonclassical transformation of educational system. Among multidimensional potential of investigated phenomenon the largest value has environmental education. Environmental education acts today as an effectual practical mechanism of transformation of educational system on the principles of sustainable development. This defines its need in analysis in the context of establishing of postnonclassical educational practices.

As basis of environmental education development lays long-term interaction between humans and nature together with vast amount of scientific data about environmental degradation. Till the middle of $20^{\text {th }}$ they created the base for developing of international cooperation of governmental and nongovernmental sectors of environment protection sectors within the UN. Therefore it prompted to creation of environmental education concept.

Environmental education was proposed by UNESCO and UN Program of environmental protection as maim method of harmonization of interaction between humans and nature. Conference on Environmental Protection in Stockholm (1972) adopted recommendation about establishing of the International Environmental Education Program. At the beginning of 1975 Program was created by UNESCO in cooperation with UN Environment Commission. In 1977 Tbilisi Intergovernmental Conference on Environmental Education was held, that became an important event in formation of environmental education. UN conference on environment and development in Rio de Janeiro (1992) expanded bounds of Tbilisi conference and became groundbreaking event in international community's life. The decision of transforming of sustainable development conception into the system of spiritual and professional attitudes of mankind was adopted.

In national doctrine of development of education of Ukraine in $21^{\text {st }}$ century and Concept of continuous environmental education it is said, that education of the person in the spirit of responsible attitude to the environment on the basis of her awareness of the unity of man and nature, developing behaviors that motivate and encourage environmentally friendly activities is one of the important and socially significant tasks of the modern school. In another words, it is needed to orientate action to from new generation with new type of environmental consciousness, which will be able to provide sustainable development of society in today conditions.

It should be noted that transition to sustainable development is considered as single option way out of critical situation in interactions between humans, society and nature. Main context of the third millennia is conditioned by establishing of socio-economic principles of civilization of sustainable type and formation of new identity. Establishing 
of such identity also suggests humans return to nature, but with already ecological spiritual and ethical content. We mean environmentalization both social consciousness and all spheres of mankind's living in general. Main principle of strategy of sustainable development means balanced parity of society's ecological and economic interests. Environmentalization of social consciousness is done in this aspect.

As the most important trait of education for sustainable development is systematic environmentalization of education. It is quiet understandable, because education for sustainable development in context and methodology has been formed on basis of environmental education. Environmental education is considered as systematic toolkit of formation of basic attributes of entering to education for sustainable development's sphere for modern person - critical thinking, holistic ecological outlook, subject-value attitude to the environment, eco-cultural values. Domestic specialists define the tasks of environmental education in modern conditions as followings:

- $\quad$ nurturing understanding of modern environmental problems of the state and the world, awareness of their importance and relevance for social development;

- $\quad$ forming an understanding of the need to coordinate the strategy of nature and human development on the basis of the idea of universality of natural features and selfrestriction;

- developing of personal responsibility for the state of the environment at local, regional and national levels;

- developing skills to overcome environmental problems; promoting the elimination of the ecological crisis, on which successful rehabilitation depends on the environment (Kutsenko \& Thrillenberg, 2014: 21)

As we see, today environmental knowledge has already ceased to be the aim of environmental education. Environmental culture and thinking are of a greater value as ecocentric values and mentality and practice-oriented habits of naturalistic behavior. According to this, we can consider essential increase of environmental education that nowadays includes environmental thinking, ecosystematic values, environmental mindset, environmental morals, environmental culture, naturalistic behavior patterns and lifestyle. In education in general missions of environmental educational are prevailing above environmental training in modern sense - uncovering the inner potential of the individual to become itself, oriented towards environmental values and based on them practical activity. As in case of education for sustainable development in general, one of its results - environmental culture - is already considered not in contextual field that is a part of personalistic and social culture connected with environmental thinking and activity priorities, but in attributive too, as a new culture context that is native to society of sustainable development.

So, environmental education is actual socio-economic, psychological and pedagogical, humanitarian and ethical problem, whose context and sense can be defined as process of person's formation of environmental culture, main characteristic of which is responsible attitude towards nature as universal value. Most researchers accent that this problem has only interdisciplinary character and covers all sections of educational system. Based on the fact that education by itself is continuous process, environmental education also is continuous, systematized educational process. In our opinion, recognized by the world community right of every person for adequate environment and development can be 
considered as main imperative of environmental education. Environmental education must become one of the most important educational reasons: not only our physical health (in medical sense) but mental health too (in metaphysical sense) depends on environment.

In the light of conception of sustainable development environmental education gets primary status, strategic direction in educational system. Fostering environmental responsibility as a measure of human freedom in the face of an environmental crisis becomes main task of environmental education. Next aspects can be highlighted:

1. Development of ecological consciousness through multilateral familiarity with the principles of organization and functioning of different ecosystems;

2. Determining the place and role of man in the biosphere;

3. Raising the need for environmental activities;

4. Forming a mentality based on sustainable development.

It is obvious that every aspect transmits a worldview function and demands some concretization according to main steps of studying.

Ecology as a branch of knowledge influences of educational system a lot, where educational aim are reoriented and corrections are made into specialist's training. Vaster worldview is being formed. Under environmental influence in educational system methods of cognition and values orientation of mankind are being changed: from traditional "consumable" attitude towards nature to delicate, honorable, and reverent.

Understanding of terms of ecosystem, environmental interaction, environmental contradiction, environmental development and environmental stability that show different phenomena and processes in ecology must be in the core of environmental education. They give an opportunity not only describe any ecosystem step-by-step, but also provide connection between theoretical and practical level of cognition. The term "ecosystem" must have information about level of organization, structure and components of different ecosystems; "environmental interaction" - show systems dynamics, its survival and development conditions, dynamical balance, self-regulation that is natural for ecosystems. Term "environmental contradiction" characterizes difficult relation between human and nature. Term "environmental development" must be understood as increasing or decreasing in ecosystem's variety, steps and speed of theirs transforming. Term "environmental stability" must include survival conditions and longterm development of central object of ecosystem.

It will be reasonable to mention that in several course books thus ontological scheme of creating of environmental knowledge has already been realized. But, considering concept of sustainable development, along with this approach problem oriented approach to environmental education should appear. First approach is closely related with traditional educational system, fits in harmoniously into its methodic, style, and values but isn't enough for these days. Undoubtedly, either in basis of problem-oriented or in basis of "outstripping" environmental education means of sustainable development and environmental security with orientation towards fulfilling environmental security during society's transition towards sustainable development must govern.

Nowadays, understanding of security has also undergone several metamorphoses. If earlier, before UN Conference in Rio de Janeiro and Johannesburg where main purpose of mankind was formulated: survival and sustainable development - security meant 
protection against different threats and abnormalities from historical-natural process, but now only those society or country that realizes model of sustainable development can be considered as secure. Modern civilization is an unstable system. It is an example of an unsustainable development because of being created on principles of free will and omnipotence. Unsustainability can be seen in global environmental and anthropological problems that pose a threat not only to mankind, but for all living things in general. Main factors on instability such as demographical blast and economic growth are strengthening anthropogenic pressure on biosphere.

Now it is about providing security exactly during transition to new civilizational model of sustainable development. Thus any security strategy either environmental or anthropological must be based on principles of concept of sustainable development that is absolutely new approach at the security problem. It means regulated transition of civilization to model of sustainable development. Now security strategies of every country must include global sustainable development demands, realizing that it is impossible to solve modern society's global problems either on local or national level. Biosphere's preserving in a necessary condition for civilization's sustainable development.

In must be mentioned that on the current step of Ukrainian society's development consciousness of most of the population is not ready to perceive new environmental idea. Serious work in this direction must be done, starting from legislative acts. Principles, ideas of environmental security and sustainable development must be included in all current and future concepts, programs, legislative acts, including educational acts.

Environmental education system must include both new teaching of traditional subjects and implementing of new disciplines that would help to form general knowledge about human and nature interaction. For example:

- global ecology aims to investigate the impact on the biosphere of anthropogenic, space, geophysical and other influences;

- social ecology aims to investigate the issues of preserving human health in the existing ecological and social conditions;

- buman ecology must take into account human interests to improve the conditions of its life, its impact on the environment, analysis of motives and patterns of their activities etc.

Context of environmental education is defined by idea of studying from the whole to pieces: biosphere - ecosystems - natural communities, population, concrete organisms, and must include not only scientific knowledge, but be complemented by works of art and literature. In the process of environmental education integration of scientific knowledge about human and nature interaction and relevant socio-cultural codes that will lead to education humanization must be done.

Scientific aspect of the context of environmental education includes natural-scientific, sociological and technological patterns, theories and terms that characterize biosphere and society, human's production and economic activity and its influence on ecology of nature.

$V$ alue aspect forms moral, esthetic attitude towards environment, teache to see the beauty of our world. 
Regulatory aspect includes a system of rules and regulations, regulations and prohibitions of an ecological nature.

Activity aspect is directed on organization of human activity, prevention of harm to the environment, formation of practical actions of ecological character, ability to be active in solving ecological problems.

In general, modern environmental education must be aimed for future, be based on ideas of coevolution of humans and nature, sustainable development of biosphere. It must be aimed for overcoming already formed society's stereotypes because of formation of spiritually-moral, environmentally competent person and creating of conditions of development that will become a guaranty of social stability.

Vital aim of conception of sustainable development is mortification of consumer instincts of mankind. Without decreasing of role of economic and law mechanisms, it is obvious to change mankind's mentality by the means of increasing of environmental culture.

Prerequisites for formation of environmental culture create understanding of severity and scale of environmental problems, detection of its global and regional character, and development of educational system, education and information. In its outlines relations between humans and nature appear as spiritually-moral problem. Environmental culture is also a complex of material and spiritual values and also ways of human activity that determines the relevance of socio-cultural process to the conservation of the environment. Thus environmental culture can be considered as intellectual-spiritual basis of civilization of sustainable type.

Environmental culture includes knowledge of what need to be done, how it must be done and, most important, readiness to take part in preserving of the environment. Striving to solve global problems we cannot forget about everyday things. The need to study problem of environmental culture is caused not only by the threat of environmental crisis. Human's consciousness evolution is involved as the phenomenon of cultural and historical field. That is:

- $\quad$ changing the paradigms of social consciousness from economic of $19^{\text {th }}-20^{\text {th }}$ century to environmental of 21 st;

- the search for the answer to the questions about the nature of man and the gradual awareness of the triune nature of his essence as a being of biological, social and spiritual;

- human evolution as the subject (carrier) of consciousness: from the subject of individual and group (social) development to the subject of development of the planet as a whole.

Basis of environmental culture is environmental morality that consists in understanding of the need to coordinate its actions/ actions of a group of personalities with society's interests.

Taking into account the important role of education in secondary and high school, we think that success of this education mostly depends on education of environmental culture in each and every family. Modern tendency of development of environmental education activities in the world is combining of efforts of NGOs and funds, representatives of governmental structures, business, all interested persons in shaping the ecological culture of society and every person. 
In general education schools new educational model are implemented that are based on humanitarian-aesthetic and natural-subject integration. Disciplines must be environmental oriented and aimed for developing of intellectual and spiritual spheres of personality. Such integration gives an opportunity not only to prepare pupils to systematic, scientific understanding of the world and its environmental problems, but also strengthen the need of knowledge and active nature preserving activity. But traditional system of continuous environmental education is not so effective to form environmental culture. This is due to accent being placed on environmental knowledge, with the result being good environmental erudition but low level of nature preserving activity, weakly expressed subjective, ethical attitude to nature. The idea of selfdevelopment of the personality, for which moral-ethical principles and laws of spiritual development are determining, comes to the fore.

According to the third idea, if we don't mention theoretical and methodological differences that take place in spiritual sense and we get a look at this phenomenon from metatheoretical perspective, spirituality can be identified as a value-semantic form of man and his being, form that is a method of man's self-determination, self-actualization, and self-development in its being. For sustaining of the transition of civilization onto the way of sustainable development it is needed to reconsider traditional values, refuse from several "benefits" of civilization, from habit to look at nature as an "endless storage". Environmental aspect of educational system is closely related humanitarian aspect. It is rather justified, because if we don't take into account biospheres preservation and provide people with favorable environmental conditions, we can't raise a question about continuous development of mankind.

Perspective of establishing environmental ethics is related to problems of environmental culture. Arousing of scientific interest to problems of environmental ethics was provoked by environmental crisis that is constantly deepening. Environmental ethics as a scientific direction has formed in $80^{\text {th }}$ of last century. Ethical thoughts about living nature were expressed by founders of all world religions. In the last decades of $20^{\text {th }}$ century environmental ethics' problems were actively discussed in foreign philosophy. O. Leopold and A. Shveizer are considered to be founders of environmental ethics as a science. Nowadays environmental problems are discussed all over the world.

Evolution of ecology as a new ethics wears off quickly. Ecology is like a weapon of biosphere both in confronting destructible aggression of technosphere and in battle for people's minds, which are being destroyed by the predatory ideology of corporations. Definition of environmental ethics does not have any contextual differences. Overall, environmental ethic can be defined as a doctrine/interdisciplinary science about moral relations between man and nature based on considering nature as a moral partner, equality and equivalence of all living things, and also limitations on people's rights and needs.

It would be rightly to remind about two cornerstones of the doctrine in the context of valuable aspects of environmental ethics - science and religion. Both value installations are needed to form environmental ethics, providing clash between two substantive but different spheres of man's existence.

Importance of science for environmental ethics lies no less than in three aspects: 
- formulation of restrictions that are impose on human behavior by social and biological structures; to formulate the constraints imposed on human behavioral, social and biological structures;

- $\quad$ more or less reliable assessment of the impact of decision-making on humans and nature;

- $\quad$ formation of value outlook within which we make ecological decisions.

It is obvious that science is an important source of ethics, but it's not enough to create environmental ethics. If "oblivion of being" (M. Heidegger) is attributing to scientific approach, religion finds its purpose in showing the way to entity (God) for a man. Scientific-technological intension of consciousness arises from being interested in the benefits of the world, religion, per contra, defines reverent-selfless attitude towards entity in general. Only developing of science and technology isn't enough to free us from environmental crisis, unless we turn to religion as a spiritual source of environmental ethics.

Thus, ethics-axiological roots of environmental crisis of modern techogenetic civilization lie inside cult of consumer priorities and underestimation of nature's value. Way out of the crisis is seen in developing of new value-normative strategies that will let to increase the value of Life and approve environmental behavior. Basement of environmental ethics, as a foundation for environmental culture, are both science and religion in equal parts. In our opinion, philosophical knowledge must bring a valuable contribution into formation of environmental ethics. Taking into account collected visions about formation of moral norms in society and personality's morality, philosophy is capable of proposing the strategy of implementation of environmental ethics into social consciousness.

In order to solve the conflict between the need to support stability of technosphere and preserving resources and ecosystem, that is still being solved in a form of gradual planetary degradation of the last, it is possible to use informatization that has anthropogenic character combined with shifting accents in education to morality and responsibility for future generations, in order to turn back the tendency mentioned above.

Ecologization in modern conditions means optimization of relations of humans with environment that find concretization in the concept of sustainable development. Ecologization of education foresees concrete change in education in methodological and contextual field based on the conceptual scientific environmental knowledge. Problems of ecologization must be solved using step-by-step change of social organization of society in the outlines of environmental (including moral) imperative that requires formation of man's worldview, its shift to human values.

Today environmental education is the most efficient mechanism of postnonclassical transformation of educational system in the context of the concept of sustainable development. It is complex system of interdisciplinary knowledge, moral-ethic values, methods and methodology of creating of educational activity. Result of environmental education is formation of environmental culture and environmental consciousness as a basis for practical reliance on the activities of individuals and society as a whole. Actualization of the problematic of environmental values has led to creating of new environmental ethics that is a basement for implementing new moral-value relations 
between man and nature. New ethical problematic and ontological structure of creating of environmental knowledge demands serious philosophical-cognitive comprehension of the studied component of the education system for sustainable development.

\section{Conclusion}

Thus, in mankind's outlines survival imperative must mean imperative of transition to new sustainability of socionatural evolution, mechanisms of which have the dominance in harmonization processes being transferred to social intellect that is new philosophical category. In institutional field it is seen as unity of science, culture and education, unity of social consciousness and knowledge that provides realization of future management functions, thus transforming into part of socionatural homeostasis and becoming new noospheric social intellect. Formation mechanism of social intelligence recreation, which substance is knowledge, is education as a social and civilizational institute. In basement of this process lays an imperative of global-civic man's fostering combined with moral-noospheric imperative that is based onto new nonclassical morality which value and priority system are part of deep synthesis of morality, spirituality and intelligence, and also noospheric-environmental imperative as a new mindset basis. Modern environmental education as a primary method of harmonization of interaction between man and nature isn't limited to principles of nature protection but is by itself interdisciplinary basis for education of sustainable development. From philosophical point of view the biggest value has ontological scheme of creating of environmental knowledge in unity with problem-oriented approach. Cumulative result of environmental education is formation of environmental culture, in outlines of which relations between man and nature are spiritual-moral problem. It is better to overlook environmental education and culture as a mechanism of formation of spirituality of sustainable development. Principles of environmental ethics lay as a basement. It means moral relations between man and nature that are based onto appreciation of nature as amoral partner and also on limiting man's rights and needs. Education by itself is a main mechanism of formation of social intellect as a basis for managing in "knowledge community". Realization of this function requires rebuilt of education on imperative principles that come from the concept of sustainable development - noospheric consciousness, environmental education and fostering, socionatural value systems, etc.

\section{References}

Aichi-Nagoya Declaration on Education for Sustainable Development, adopted in Aichi-Nagoya, Japan, from 10 to 12 November 2014 (2014). http://www.jstor.org/stable/pdfplus/1501686.pdf

Andersone, R. (2015). The Content Reform of Education for Sustainable Development. Rural Environment. Education. Personality. (REEP). Proceedings of the International Scientific Conference. Jelgava: LLU. (8). pp.75-81.

Agenda for the 21st Century

http://www.un.org/documents/decl conv/conventions/agenda21_ch36.shtml

Bonn Declaration, adopted in Bonn, Germany on 31 March to 2 April 2009 (2009). http://unesdoc.unesco.org/images/0018/001887/188799e.pdf 
Dlouháa, J, Pospíšilováb, M. (2018). Education for Sustainable Development Goals in Public Debate: The Importance of Participatory Research in Reflecting and Supporting the Discussion Process in Developing a Vision for Czech Education. Journal of Cleaner Production, 172, 4314-4327, doi.org/10.1016/j.jclepro.2017.06.145

Education for Sustainable Development Goals: Learning Objectives (2017). http://unesdoc.unesco.org/images/0024/ 002474/247444e.pdf

Global Action Programme (GAP) on Education for Sustainable Development (ESD): Goals and Objectives. UNESCO (2014). https://en.unesco.org/gap/goals- and-objectives?language=en

Grosseck, G., Țîru, L. G., \& Bran, R. A. (2019). Education for Sustainable Development: Evolution and Perspectives: A Bibliometric Review of Research, 1992-2018. Sustainability, 11 (21), 6136. doi: 10.3390 / su11216136

Khmelevskaya, O.M. (2018) Education for sustainable development: content and institutions. Demography and the social economy. (1). pp. 29-42.

Klepko, S.F. (1998) Integrative education and the polyformism of knowledge. Kyiv - Poltava - Kharkiv: POIPOPP.

Korneva I.M. (2018) Phenomenon Of Education for Sustainable Development: essence and modern features of the concept. Ukrainian Pedagogical Journal. (2). pp. 113-123.

Kutsenko, V., Thrillenberg, G. (2014) Environmental education is an important tool for sustainable development. Economics of environmental management and environmental protection. (7). pp. 20-22.

McKeown, R. (2006). Education for Sustainable Development Toolkit. Paris: Printed in UNESCO's workshop.

Nikolaev, K.D. (2015) Advance Education for Sustainable Development as an Innovative Form of Organization of the Teachers' Educational Space. Scientific notes of the National Pedagogical University. Pedagogical and Historical Sciences (126). pp. 116-124.

O'Flaherty, J. \& Liddy, M. (2018) The impact of development education and education for sustainable development interventions: a synthesis of research, Environmental Education Research, 24: 7, 1031-1049, DOI: 10.1080 / 13504622.2017. 1392484.

Pometun, O.I. (2015) Pedagogical principles of education for sustainable development in the Ukrainian school. Ukrainian Pedagogical Journal. (1) pp. 171-182.

Sichko, I. (2016) Environmental education and upbringing as elements of a sustainable development strategy. Scientific Bulletin of Mykolayiv National University named after V.O. Sukhomlinsky. Pedagogical Sciences. (4) pp. 173-178.

Sinakoua E., Boeve-de Pauwa, J., Goossensb, M., Petegemc, P.V. (2018). Academics in the field of Education for Sustainable Development: Their concepts of sustainable development. Cleaner Production Journal, 184, 321-332. doi.org/10.1016/j.jclepro.2018.02.279

Sustainable Development Goals: Ukraine. National report. Ministry of Economic Development and Trade of Ukraine (2017) .http://www.idss.org.ua/ monographs / 2017_SDGs_NationalReport.pdf 